\section{LETTER TO THE EDITOR:}

Dear Sir,

Re. Paper by Dhakal, Khare and Mander "Economic Payback of Improved Detailing for Concrete Buildings with Precast Hollow-Core Floors" in NZSEE Bulletin Volume 39, No 2, June 2006, pp106-119.

The above article outlined a potential decision making tool for evaluating retrofit solutions based on expected annual loss. The tool, with further refinement, may prove to be useful; however, the conclusions and assumptions used in the article appear very questionable. For example the results indicate (figure $4 \mathrm{~d}$ ) that approximately $30 \%$ of modern structures will survive a 2,500 year seismic event with no damage and $40 \%$ will only sustain slight damage. Given that most structures are designed to exhibit inelastic action in a 500 year return period seismic event, the estimate performance of "modern structures" appears dramatically over stated.

There are several questionable assumptions in the article, the most obvious being-

1. The authors link the performance of Jeff Matthew's test specimen to the performance of all pre 2004 Hollowcore buildings. Jeff's test was designed to incorporate every possible feature which would probably deteriorate the performance. Features included-

a. Seating lengths less than specified in NZS3101:95. The provided seating lengths were $20 \mathrm{~mm}$ and $40 \mathrm{~mm}$. The minimum required by NZS3101:95 was $65 \mathrm{~mm} \mathrm{(L/180)}$ plus an allowance for tolerances.

b. The units were bedded on a high strength cementitious grout meaning that the units adhered to the supports.

c. The central column was not tied back into the floor as required in NZS3101:95.

d. The span of the Hollowcore was twice that of the adjacent beam.

e. The frame was designed to be fully ductile, and to the flexibility limits of the loading standard.

f. The hollowcore unit adjacent to the column was cut to fit around the column.

It would not be typical for all of these features to be incorporated into an average structure, and nor was it the intention of the test for it to be typical. The idea being that if the specimen performed adequately there could be reasonable confidence that all structures would perform adequately.

2. Damage states are presented (DS1 to DS9) and then a loss value (expressed as a fraction of the building cost) is applied to each damage state. The outcome of this assumption is that the same repair cost is assigned to the Matthew's tests above $0.35 \%$ drift to that of a modern building which has been subjected to drifts of between 2 and $4 \%$. Above $0.35 \%$ drifts in the Matthew's tests, hairline cracks were observed at the ends of some of the hollowcore units. At most the repair would be to place a precautionary angle bracket under the unit. How can the cost of this be considered the same as a " modern building" which has experienced drift of $2-4 \%$ ?

3. The assumption that buildings which have experienced drifts of $2-4 \%$ will be repairable is extremely questionable. How will the building be straightened as it is likely that residual inter-storey drifts will exist?

4. The paper provides estimates of the estimated annual loss to compare different detailing options. It ignores however that the majority of economic loss is associated with non-structural components. Ignoring this distorts the picture.

5. The drift boundaries for various damage states presented in Table 2 is very questionable. For example the table implies that the boundary for irreparable damage was $2.25 \%$ for the Lindsay test and $4 \%$ for the MacPerson test. However, the sole reason for the lesser performance of Lindsay's test was solely that the starter bars from the beam were terminated prematurely in the slab. The researcher acknowledges this. The tabled drift values do not relate to the expected performances of the respective seating details.

The article presents an interesting tool, however it illustrates the importance in any risk/financial analysis of seeking peer review of the assumptions made.

Yours faithfully

Dene Cook

Member

\section{AUTHOR'S RESPONSE: Rajesh P Dhakal and John B Mander}

This discussion paper is the Authors' response to the comments on their paper "Economic Payback of Improved Detailing for Concrete Buildings with Precast Hollow-Core Floors" published in the Bulletin of the NZSEE, Vol. 39, No. 2, June 2006.

- $\quad$ The tool, with further refinement, may prove to be useful; however, the conclusions and assumptions used in the article appear very questionable. For example the results indicate (Figure 4d) that approximately $30 \%$ of modern structures will survive a 2500 year seismic event with no damage and $40 \%$ will only sustain slight damage. Given that most structures are designed to exhibit inelastic action in a 500 year return period seismic event, the estimate performance of "modern structures" appears dramatically over stated.

$\rightarrow \quad$ The authors agree that there is room for refinement. Indeed, research is presently continuing at the University of Canterbury and elsewhere on investigating the seismic response effects on death, damage and downtime - all of which can be expressed in terms of dollars. However, we stand by our present estimates of damage as being indicative of response 
and damage outcomes to the structures that possess traits similar to the systems studied [6-8]. Note that the tested structure with improved detailing was in damage state 2 (slight damage category) until 2\% inter-storey drift; obviously this structure is unlikely to experience displacement ductility of 4 (what the modern capacity design aims for) in a design basis earthquake (DBE). In designing a structure, we strive to exceed a dependable target performance, and there is inherent conservatism in this process which we shall discuss below. We shall restrict our discussion to an exact match of the minimum standard expected of the NZ building code. Naturally, a designer is at liberty to exceed minimum standards provided that the principles of capacity design and protection are adhered to. In brief, even if design parameters are assigned values very close to the minimum required by design standards, there will be inherent overstrength in all designed structures. This is due to the use of characteristic $\left(95^{\text {th }}\right.$ percentile) strength instead of the probable $\left(50^{\text {th }}\right.$ percentile) strength. Also, strain hardening and dynamic (rate) effects add to the provided overstrength. This ensures most as-built structures perform significantly better than the milestone aimed in the basic design calculations.

To help explain this general outcome, consider the following simple example. Suppose we chose to design a structure on its probable material strengths for a DBE, rather than the customary specified strengths. Also suppose we could exactly match the required design quantity of reinforcing steel then the expected strength capacity of the principal beam members would be

$$
M_{e}=A_{\text {s provided }} f_{\text {ye }}\left(d-d^{\prime}\right)
$$

in which $A_{s \text { provided }}=$ actual provided area of reinforcing bars (which may be expected to be a certain margin in excess of design requirements, $A_{s}$ required $), f_{y e}=$ expected (median/mean) yield strength of the rebars; and ( $\left.d-d^{\prime}\right)$ $=$ internal lever arm between the top and bottom centroids of the longitudinal tension and compression steel.

In contrast to this we customarily design for a dependable specified strength as

$$
\varphi M_{n}=\varphi A_{\text {s required }} f_{y}\left(d-d^{\prime}\right) \geq M^{*}
$$

where $\varphi=$ undercapacity factor ( 0.85 for flexure); $f_{y}=$ characteristic (specified) yield strength based on a $95 \%$ exceedance probability; and $A_{\text {s required }}=$ required area of reinforcing bars.

The ratio of the expected (in-situ) to the specified (design) strength thus becomes

$$
\frac{M_{e}}{M^{*}}=\frac{1}{\phi} \frac{A_{\text {s provided }}}{A_{\text {s required }}} \frac{f_{y e}}{f_{y}}
$$

Taking some typical values for these ratios gives

$$
\frac{M_{e}}{M^{*}}=\frac{1}{0.85} \times 1.10 \times 1.25=1.62
$$

Additional strength also arises from dynamic loading rate effects $(15 \%)$ and redundancy $(15 \%)$. In total, the expected $\left(50^{\text {th }}\right.$ percentile) strength is in excess of a factor of two times higher than the code-based design capacity. However, for simplicity let us restrict the total dynamic overstrength to, say 2.0.

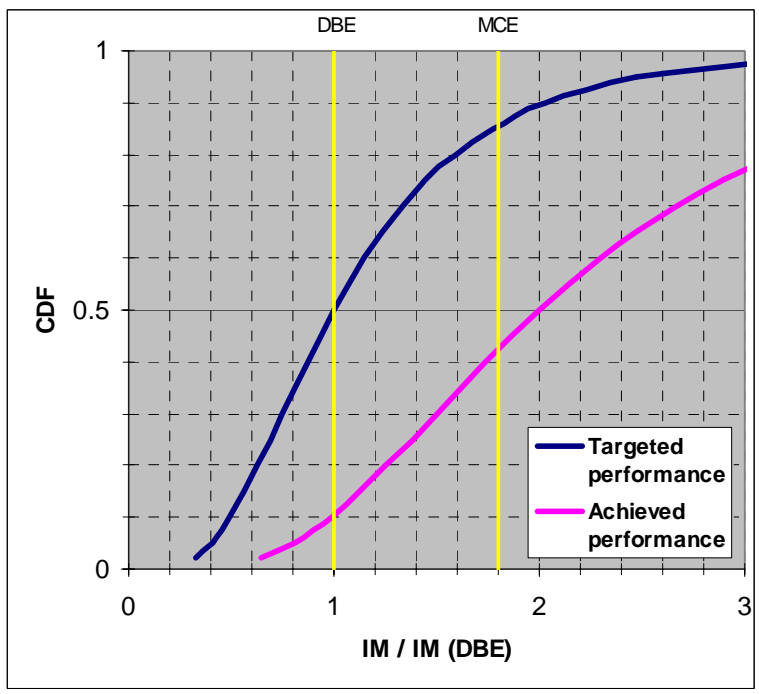

Figure 8. Fragility curves for a DS3 and DS4 boundary (interpreted as $\mu=4$ ).

Now if we design a structure for an overall structure ductility factor of $\mu=4$ we can assume that this is at the interface between damage state 3 and 4 - that is, the end of repairable damage and the onset of irreparable damage. For the case of the design based on probable $\left(50^{\text {th }}\right.$ percentile or median $)$ material strength we can expect that there is a 50 percent chance of achieving this for a DBE. Due to the aleotoric uncertainties associated with the ground motion variability and randomness in material strengths, a fragility curve similar to the leftmost curve shown in Figure 8 results. In addition to there being a 50 percent chance of exceeding this performance limits for DBE ( $10 \%$ in 50 years) there is an $85 \%$ chance that this damage state has been exceeded for a maximum considered event (MCE), having $2 \%$ probability of occurrence in 50 years. Figure 8 also plots, in the rightmost curve, the fragility function based on the probable achieved performance. For a realistic structure designed to the specified properties with $100 \%$ inherent overstrength, the probability of reaching the design limits reduces from $50 \%$ to $10 \%$ for the DBE. Similarly, there is a reduction from $85 \%$ to $42 \%$ for the level of MCE when the design conforms to realistic mechanical properties.

It is thus evident that structures should perform better than intended by design. It is for this reason that fewer structures are damaged in earthquakes than that might be expected by design. Take for example the 1994 Northridge earthquake. Many regions of the greater Los Angeles region experienced ground motion in excess of the DBE motion (PGA $=0.4 \mathrm{~g})$. In fact PGAs 
of $0.8 \mathrm{~g}$ were not uncommon. And yet only a modest number of structures sustained irreparable damage or collapse; many of these failures were attributed to detailing or construction flaws. In fact, the observed damage is consistent with the rightmost fragility curve presented in Figure 8.

6. The authors link the performance of Jeff Matthew's test specimen to the performance of all pre 2004 Hollowcore buildings. Jeff's test was designed to incorporate every possible feature which would probably deteriorate the performance. Features included-

a. Seating lengths less than specified in NZS3101:95. The provided seating lengths were $20 \mathrm{~mm}$ and $40 \mathrm{~mm}$. The minimum required by NZS3101:95 was $65 \mathrm{~mm}(L / 180)$ plus an allowance for tolerances.

b. The units were bedded on a high strength cementitious grout meaning that the units adhered to the supports.

c. The central column was not tied back into the floor as required in NZS3101:95.

d. The span of the Hollowcore was twice that of the adjacent beam.

e. The frame was designed to be fully ductile, and to the flexibility limits of the loading standard.

f. The Hollowcore unit adjacent to the column was cut to fit around the column.

It would not be typical for all of these features to be incorporated into an average structure, and nor was it the intention of the test for it to be typical. The idea being that if the specimen performed adequately there could be reasonable confidence that all structures would perform adequately.

$\rightarrow$ The aim of this paper is to interpret the comparative results of the well-known tests conducted at the University of Canterbury [6-8] in more easily understandable terms (damage, loss, dollars) compared to the common performance parameters such as drift, ductility etc. The paper takes the experimental results [6-8] without trying to reinterpret them. If the reader gets an impression that this paper links Matthews' specimen with all pre-2004 Hollowcore buildings, that has not been intended. The name "buildings with Hollowcore floors built to pre-2004 standards" was use to distinguish this with the others that were built to the post-2004 amendments of NZS3101. It should be noted that these experiments formed the basis for modifying the New Zealand Concrete Structures Standard NZS3101.

7. Damage states are presented (DS1 to DS5) and then a loss value (expressed as a fraction of the building cost) is applied to each damage state. The outcome of this assumption is that the same repair cost is assigned to the Matthew's tests above $0.35 \%$ drift to that of a modern building which has been subjected to drifts of between 2 and 4\%. Above $0.35 \%$ drifts in the Matthew's tests, hairline cracks were observed at the ends of some of the Hollowcore units. At most the repair would be the place a precautionary angle bracket under the unit. How can the cost of this be considered the same as a "modern building" which has experienced drift of $2-4 \%$ ?

$\rightarrow \quad$ The philosophy of assigning loss ratios (LR) to damage states (DS) is not an assumption, this is an established methodology followed in loss estimation [21]. The values of loss ratio used for different damage states are based on engineering judgment and empirical observations in previous earthquakes. Admittedly there is some imprecision associated with assigning LR to DS 2, 3 and 4. Probabilistically, this imprecision is accounted for by assigning a value to the epistemic uncertainty. Overall, EAL values may change depending on LR assigned, but the relative standing of each design will remain the same.

Regarding the drift values, Matthews listed in Table 46 of his PhD Thesis [6] that DS3 (moderate damage) began at $0.35 \%$ drift and lasted up to $2 \%$ drift in his test. Lindsay listed in Table 3-4 of her ME Thesis [7] that the range for DS3 in her specimen was from $2 \%$ to $2.25 \%$. The DS3 range in terms of inter-storey drift was listed as $2 \%$ to $4 \%$ for modern frame buildings in Lindsay's Thesis Table 3-4, which was the same as what MacPherson's test result suggested; see section 3.5 of MacPherson's ME Thesis [8]. The analysis presented in this paper adopts these values from the respective theses. As loss ratios (indicative of repair cost) depend on the DS and not on storey drifts, it is expected that the same loss is incurred due to 0.35 $1.9 \%$ drift range in building floors tested by Mathews, and $2 \%-2.25 \%$ and $2 \%-4 \%$ drift in floors tested by Lindsay and MacPherson, respectively. It is true that had a steel angle bracket been under the unit, the floor may be deemed safer and the damage state at that stage would have been classified below DS3 resulting in a lesser loss. Nevertheless, putting the bracket after the cracks have occurred and the units have slipped does not cure anything. This underscores the fact that even simple (cheaper) but appropriate connection detailing improvements may be able to make the system more robust, both structurally and economically.

8. The assumption that buildings which have experienced drifts of $2-4 \%$ will be repairable is extremely questionable. How will the building be straightened as it is likely that residual inter-storey drifts will exist?

$\rightarrow \quad$ It is only in the best detailed structure that the DS3 (moderate, repairable damage) spans between 2\% and $4 \%$ interstorey drift. In other two lesser quality cases (structures tested by Matthews and Lindsay), the repairable damage range ends at $1.9 \%$ and $2.25 \%$ interstorey drift, respectively. MacPherson's thesis reports "The residual drift after the $+-2 \%$ cycles was around $1.1 \%$ and the structure had suffered moderate but possibly repairable damage.", "After the completion of the Phase 2 transverse loading to $+-3 \%$ the residual drifts were approximately $1.6 \%$ and the structure had suffered moderate damage but was still in a repairable state" and "At $+-4 \%$ drifts, significant amounts of concrete had become loose and fallen from the plastic hinge zones ....Although the structure was still in a stable condition, the damage in some areas became irreparable and major components would need to be 
replaced for further structural use." Naturally, the authors trust the veracity of these statements moreover, they were all independently peer reviewed. Furthermore, for the best-detailed case (structure tested by MacPherson), the $4 \%$ interstorey drift used as the limit of repairable damage is close to the corresponding value $(3.75 \%)$ recommended by HAZUS [21] for low rise concrete moment frame buildings. Thus, the difference in the interstorey drift limits (for different damage states) for different levels of design robustness are consistent with the loss estimation practice in the US $[21,22]$.

9. The paper provides estimates of the estimated annual loss to compare different detailing options. It ignores however that the majority of economic loss is associated with non structural components. Ignoring this distorts the picture.

$\rightarrow \quad$ Yes, depending on the utility of the building, in many cases the majority of the loss may be contributed by the non-structural (including content) damage. Furthermore, downtime and death/injury should also be taken into account to come with the most complete picture of total loss to the community. This is the subject of ongoing research.

10. The drift boundaries for various damage states presented in Table 2 is very questionable. For example the table implies that the boundary for irreparable damage was $2.25 \%$ for the Lindsay test and $4 \%$ for the MacPherson test. However, the sole reason for the lesser performance of Lindsay's test was solely that the started bars from the beam were terminated prematurely in the slab. The researcher acknowledges this. The tabled drift values do not relate to the expected performances of the respective seating details.

$\rightarrow \quad$ The drift boundaries for different damage states are not strictly the interpretations of the authors. As mentioned earlier, these values are given by the experimenters in the theses [6-8]. Hence, the authors feel that questions related to the interpretation of the experimental observations fall outside the scope of this paper. Notwithstanding this, the delay in the onset of irreparable damage in a well-detailed structure is also supported by international practice [21, 22].

\section{References}

21. FEMA. Multi-hazard Loss Estimation Methodology Earthquake Model. HAZUS-MH-MR1, 2003.

22. Kircher C.A., Bouabid J. and Morrow G.C. "When the Big One Strikes Again - Estimated Losses due to a Repeat of the 1906 San Fernando Earthquake". Earthquake Spectra, 2006; Vol. 22, No. 2: pp. $297-$ 339. 


\section{GENERAL INFORMATION}

\section{NZSEE HOME PAGE ON THE INTERNET}

The Society's home page address is:

http://www.nzsee.org.nz

\section{COMING CONFERENCES AND SYMPOSIA}

March 2007

March 30- April 1, 2007

NZSEE Annual Conference \& AGM, Palmerston North. See website for details.

June 2007

June 27-27, 2007

Ninth Canadian Conference on Earthquake Engineering, Ottawa, Canada. For details and how to submit an abstract, see www.9ccee.ca .

December 2007

December 4-6, 2007

Pacific Conference on Earthquake Engineering, Singapore. Organised by Nanyang Technical University, Singapore (NTU). See Society website for details.

\section{October 2008}

October 12-17, 2008

$14^{\text {th }}$ World Conference on Earthquake Engineering, Beijing, China. Details on http://www.14wcee.org

\section{STRONG MOTION RECORDINGS}

Processed strong-motion records from the GNS network can be downloaded from the GeoNet webpage

www.geonet.org.nz. Proceed via "Data centre" and "Strong motion data" to ftp.geonet.org.nz/strong/processed. The data includes the following

- $\quad$ raw files from digital instruments,

- unfiltered acceleration time-histories

- filtered time-histories for acceleration, velocity and displacement, and

- acceleration, velocity and displacement response spectra.

All are in ASCII (text) format and are accompanied by plots in postscript format. The recording period covered is from 1966 to present, but be aware that earthquake parameters in records from the most recent 12-month period are not final and may be changed in the future.

Records from the period 1966 to 1999 are also available from the COSMOS site (www.cosmos-eq.org).

For further information about the data, bulk supply of records, or to provide feedback, contact Jim Cousins at j.cousins@gns.cri.nz.

\section{PEOPLE}

\section{New Members.}

The following persons and a corporation have recently been admitted as members of the Society:

Franco Anaya, Roberto

Tapp, David

Mahmood, Hamid

Hill, Jonathan

Patel, Sanjay

Pinkney, Steve

Sullivan, Timophy

Ying, Jinfei
Christchurch (student)

Darlington, U.K.

Auckland (student)

Wellington

Auckland

Palmerston North

St Albans, U.K.

Auckland (student) 


\section{6/2007 MANAGEMENT COMMITTEE}

Administrative Secretary NZSEE

Mr Derek Wilshere

PO Box 41069

Eastbourne

Wellington 6340

NEW ZEALAND

Email: derek.wilshere@xtra.co.nz

\section{President}

Prof. Michael Pender

University of Auckland

Dept of Civil \&Environmental Engineering

P Bag 92019

Auckland

Fax: (09) 3737462

Email: m.pender@auckland.ac.nz

\section{Immediate Past President}

Dr Mark Stirling

Inst. Geological \& Nuclear Sciences

P O Box 30368

Lower Hutt

Fax: (04) 5666168

Email: m.stirling@gns.cri.nz

Mr Graeme Beattie

BRANZ,

Private Bag 50908

Porirua

Fax: (04) 2356070

Email: graemebeattie@branz.co.nz

Mr P. Brabhaharan

Opus International Consulting

PO Box 12003

Wellington

Fax:

Email: p.brabhaharan@opus.co.nz

Mr Hans Brounts

Ministry of Emergency Management

PO Box 5010

Wellington

Fax: (04) 4737369

Email: hans.brounts@dia.govt.nz

Dr. Hugh Cowan,

Inst. Geological \& Nuclear Sciences

P O Box 30368

Lower Hutt

Fax: (04) 5666168

Email: h.cowan@gns.cri.nz

Dr. Bruce Deam

Dept. of Civil Engineering

University of Canterbury

Private Bag 4800

Christchurch

Fax: (03) 3642758

Email: b.deam@,civil.canterbury.ac.nz
Mr. Warwick Kellaway

121 Maeroa Rd

Hamilton

Fax: (07) 8461175

Email: jwk@slingshot.co.nz

\section{Bulletin Editor}

Mr. Les Megget

Dept. of Civil \& Environmental Engineering

University of Auckland

Private Bag 92019

Auckland

Fax: (09) 3737462

Email: 1.megget@auckland.ac.nz

Dr Stefano Pampanin

University of Canterbury

Dept of Civil Engineering

Private Bag 4800

Christchurch

Fax: (03) 3642758

Email: stefano.pampanin@canterbury.ac.nz

Technical Development Manager

Dr. Graham Rowe

1 Flint Way

Northland,

Wellington

Phone: (04) 4757189

Fax: (04) 4757189

Email: ghr@orcon.net.nz

Dr Dean Saunders

Beca Carter Hollings \& Ferner Ltd

P O Box 3942

Wellington

Phone: (04) 473 7551W

Fax: (04) 4962536

Email: dean.saunders@beca.com 